\title{
Acetylcholinesterase Inhibitors Promote Angiogenesis in Chick Chorioallantoic Membrane and Inhibit Apoptosis of Endothelial Cells
}

\author{
Seyed Mohsen Mortazavian, ${ }^{1}$ Heydar Parsaee, ${ }^{1,2}$ Seyed Hadi Mousavi, ${ }^{1,2}$ \\ Zahra Tayarani-Najaran, ${ }^{3}$ Ahmad Ghorbani, ${ }^{2}$ and Hamid Reza Sadeghnia, ${ }^{1,2,4}$ \\ ${ }^{1}$ Department of Pharmacology, School of Medicine, Mashhad University of Medical Sciences, Mashhad 917794-8564, Iran \\ ${ }^{2}$ Pharmacological Research Center of Medicinal Plants, School of Medicine, Mashhad University of Medical Sciences, \\ Mashhad 917794-8564, Iran \\ ${ }^{3}$ Department of Pharmacodynamics and Toxicology, School of Pharmacy, Mashhad University of Medical Sciences, \\ Mashhad 91775-1365, Iran \\ ${ }^{4}$ Neurocognitive Research Center, School of Medicine, Mashhad University of Medical Sciences, Mashhad 917794-8564, Iran
}

Correspondence should be addressed to Hamid Reza Sadeghnia; sadeghniahr@mums.ac.ir

Received 31 May 2013; Revised 12 August 2013; Accepted 18 August 2013

Academic Editor: Paula Moreira

Copyright (C) 2013 Seyed Mohsen Mortazavian et al. This is an open access article distributed under the Creative Commons Attribution License, which permits unrestricted use, distribution, and reproduction in any medium, provided the original work is properly cited.

\begin{abstract}
Alzheimer's disease (AD) is one of the most common causes of dementia in the elderly. Recently, a great attention has been paid to the possible role of vascular changes in the pathogenesis of AD. Reduced microvascular density and degeneration of the endothelium are of structural cerebrovascular changes in AD. Acetylcholinesterase (AChE) inhibitors are widely used for the improvement of AD symptoms. Until now, however, the effects of AChE inhibitors on vascular changes including angiogenesis and endothelial cell apoptosis are not fully understood. In the present work, the effects of three AChE inhibitors (donepezil, rivastigmine, and galantamine) were tested on $\mathrm{H}_{2} \mathrm{O}_{2}$-induced apoptosis in human umbilical vein endothelial cells (HUVECs) and on angiogenesis in chicken chorioallantoic membrane model. Incubation of HUVEC with $\mathrm{H}_{2} \mathrm{O}_{2}$ led to a significant decrease in cell viability and an increase in the percentage of apoptotic cells. The tested drugs, at concentrations of 1-100 $\mu \mathrm{M}$, significantly inhibited the $\mathrm{H}_{2} \mathrm{O}_{2}-$ induced toxicity. Also, all donepezil, rivastigmine and galantamine significantly increased the number of vessels in the chorioallantoic membrane when injected into fertilized eggs. In conclusion, AChE inhibitors possess angiogenesis-accelerating properties and have antiapoptotic effects on endothelial cells. These effects of AChE inhibitors may be involved in their beneficial effects on AD.
\end{abstract}

\section{Introduction}

Alzheimer's disease $(\mathrm{AD})$, a progressive neurodegenerative disorder, is the primary common cause of dementia in the elderly. Intracellular neurofibrillary tangles, amyloid plaques, neuronal loss, and vascular amyloidosis are of characteristic hallmarks of $\mathrm{AD}[1]$. In spite of extensive studies, however, the molecular pathogenesis of AD is not yet fully understood. Some of the suggested mechanisms include amyloid-induced neurotoxicity, inflammatory reaction, oxidative stress, proteasome inhibitor-induced cell death, and cerebral hypoperfusion $[2,3]$.
Recently, a great attention has been paid to the possible role of vascular changes in the pathogenesis of $\mathrm{AD}[1,2$, $4,5]$. Vascular irregularities, reduced microvascular density, arteriolar and capillary atrophy, and degeneration of the endothelium are of structural cerebrovascular changes in $\mathrm{AD}$ $[6,7]$. Death or dysfunction of endothelial cells leads to dysregulation of endothelial-neuronal-glial cell interactions and therefore contributes to the onset or progression of this disease. During AD, endothelial cells can be damaged by gliaderived cytokines, heavily aggregated proteins, and oxidative stress [8]. 
Acetylcholinesterase (AChE) inhibitors, antiglutamic agents, secretase inhibitors, and anti-inflammatory drugs are of available therapeutics for management of $\operatorname{AD}[3,9]$. Cholinergic deficit is consistent and early finding in patient with $\mathrm{AD}$ and $\mathrm{AChE}$ inhibitors which increase bioavailability of ACh have proven to improve cognitive function in these patients [9-15]. Donepezil, rivastigmine and galantamine are of the most widely used AChE inhibitors, and currently approved by US Food and Drug Administration (FDA). Recent studies suggest that effects of AChE inhibitors are not limited to its cholinergic activity and other mechanisms including inhibition of glutamate-induced excitotoxicity, reducing inflammatory processes, and mitigating the effects of oxidative stress involved in their beneficial effects on $\mathrm{AD}$ $[16,17]$. It has been well documented that overproduction of reactive oxygen cause dysfunction and death of endothelial cells [18]. However, the possible effect of AChE inhibitors on oxidative stress-induced endothelial cell damage remained unclear. Therefore, this study was carried out to investigate whether donepezil, rivastigmine, and galantamine are capable of protecting human umbilical vein endothelial cell (HUVEC) against $\mathrm{H}_{2} \mathrm{O}_{2}$-induced apoptosis, an in vitro model which simulates cell damage in $\operatorname{AD}[19,20]$. Also, the possible effect of these AChE inhibitors on angiogenesis was examined using chicken chorioallantoic membrane model.

\section{Materials and Methods}

2.1. Drugs and Chemicals. The HUVECs were obtained from Pasteur Institute (Tehran, Iran). Dimethyl sulfoxide (DMSO), $\mathrm{H}_{2} \mathrm{O}_{2}$, penicillin/streptomycin solution, 3-(4,5dimethyl-2-thiazolyl)-2,5-diphenyl-2H-tetrazolium bromide (MTT), and propidium iodide were purchased from Sigma (USA). Dulbecco's Modified Eagle's Medium (DMEM) and fetal bovine serum (FBS) were bought from GIBCO (USA). Fertilized eggs were kindly provided by Morghdaran Toos Co. (Mashhad, Iran). Rivastigmine tartrate and galantamine $\mathrm{HBr}$ (produced by Ranbaxy, India) were donated by Tehran Darou Co. (Iran). Donepezil HCl (produced by Megafine, India) was kindly provided by Razak pharmaceutical Co. (Iran).

2.2. Cell Cultures and Treatments. The HUVECs were cultivated in high-glucose DMEM supplemented with FBS (10\%), penicillin (100 units/mL), and streptomycin $(100 \mu \mathrm{g} / \mathrm{mL})$. All cells maintained in humidified atmosphere of $5 \% \mathrm{CO}_{2}$ and $95 \%$ air at $37^{\circ} \mathrm{C}$. Trypsin/EDTA solution was used to passage cells whenever they were grown to confluence. The cells at subconfluent stage were harvested from culture flask and seeded overnight in 96-well culture plate (15000 cells/well) after checking the viability with trypan blue exclusion technique. Then, to determine the effect of test drugs on cell viability, the medium was changed by a fresh one containing donepezil $(0.1,1$, and $10 \mu \mathrm{M})$, rivastigmine $(1,10$, and100 $\mu \mathrm{M})$ and galantamine $(1,10$, and $100 \mu \mathrm{M})$ in the presence or absence of $\mathrm{H}_{2} \mathrm{O}_{2}(1 \mathrm{mM})$, and the cells were incubated for $24 \mathrm{~h}$.

2.3. Cell Viability Assay. The viability of cells was determined using MTT colorimetric assay as described previously
$[21,22]$. Briefly, at the end of treatment, the MTT solution $(5 \mathrm{mg} / \mathrm{mL})$ was added to each well of culture plate with final concentration of $0.05 \%$. After $4 \mathrm{~h}$, the reaction mixture was removed, and the formazan precipitate was dissolved in DMSO. The optical density of formazan dye was read at $545 \mathrm{~nm}$ against $620 \mathrm{~nm}$ as background. The percentage of viable cells was calculated as the mean \pm SEM with controls set to $100 \%$.

2.4. Cell-Cycle Analysis. The cells were seeded overnight in 12 -well culture plate $(75000$ cells/well) and treated for $24 \mathrm{~h}$ with tested drugs. Then floating and adherent cells were harvested and incubated with $750 \mu \mathrm{L}$ of a hypotonic buffer $(50 \mu \mathrm{g} / \mathrm{mL}$ propidium iodide in $0.1 \%$ sodium citrate containing $0.1 \%$ triton $\mathrm{X}-100$ ) at $4^{\circ} \mathrm{C}$ overnight in the dark [23]. Then, the cells were analyzed with a flow cytometer (BD FACSCanto, BD Sciences, San Jose, CA, USA), and the results were analyzed by WinMDI (version 2.8) software.

2.5. Chicken Chorioallantoic Membrane Angiogenesis Model. Fertilized eggs were incubated at $37^{\circ} \mathrm{C}$ and $70 \%$ relative humidity in a forced draught incubator. At day 8, a window opening is punctured on each egg and $0.01-10 \mathrm{nmol} / \mathrm{egg}$ of donepezil, rivastigmine, or galantamine was injected into the chorioallantoic sac. The control eggs received sterile PBS only. Then, the injection holes were closed by wax, and the eggs were maintained in the incubator. At day 12, the eggs were opened and the chorioallantoic membrane vasculatures were photographed using a stereo microscope equipped with a digital camera (Canon EOS 40D with Canon EF $100 \mathrm{~mm} \mathrm{f/2.8}$ USM macrolens). The angiogenic response was evaluated by counting the vessel density using Photoshop CS2 and image measurement software.

2.6. Statistical Analysis. Statistical comparison was made by one-way analysis of variance (ANOVA) followed by Tukey's post hoc test. Differences were considered significant when $P$ values were less than 0.05 . All experiments were performed three times in duplicate. The results were presented as the mean $\pm \mathrm{SD}$.

\section{Results}

3.1. Effect of AChE Inhibitors on Endothelial Cell Viability. Exposure of cultured HUVECs to $\mathrm{H}_{2} \mathrm{O}_{2}$ significantly decreased cell viability from $100 \pm 3 \%$ (control) to $64 \pm 5 \%$ $(P<0.001)$. Incubation with donepezil significantly attenuated the $\mathrm{H}_{2} \mathrm{O}_{2}$-induced cell death (Figure 1(a)). The percent of viability in the cells treated with 0.1 and $1 \mu \mathrm{M}$ of donepezil was $94 \pm 17 \%(P<0.05$ versus untreated cells $)$ and $99 \pm$ $5 \%(P<0.01)$, respectively. Also, the presence of 1,10 , and $100 \mu \mathrm{M}$ of galantamine in the cell medium increased the cell viability from $64 \pm 5 \%$ (untreated cells) to $112 \pm 19 \%(P<$ 0.05), $199 \pm 19 \%(P<0.001)$, and $144 \pm 18 \%(P<0.001)$, respectively, (Figure 1(b)). Similarly, the percent of viability in the cells treated with $1 \mu \mathrm{M}(87 \pm 11 \%, P<0.05), 10 \mu \mathrm{M}$ $(90 \pm 8 \%, P<0.01)$, or $100 \mu \mathrm{M}(92 \pm 7 \%, P<0.01)$ of 


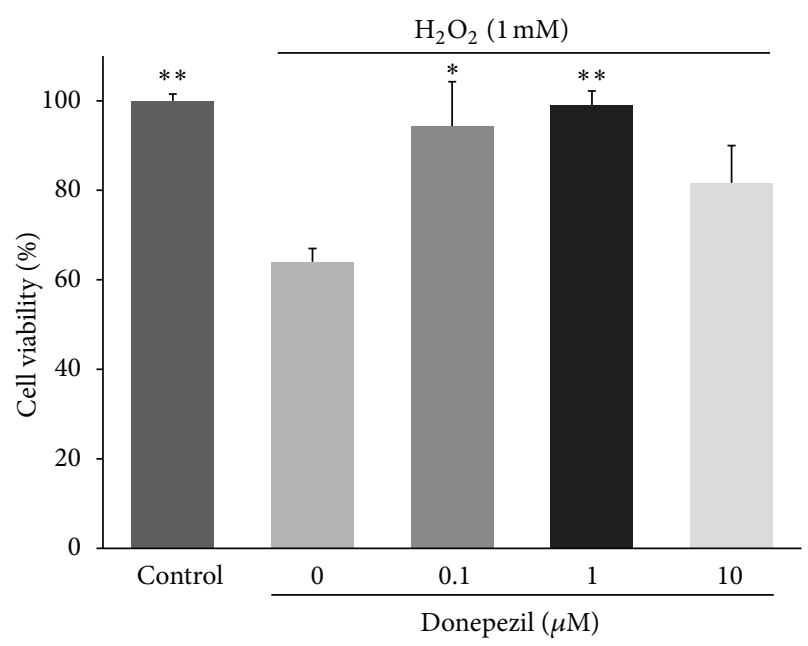

(a)

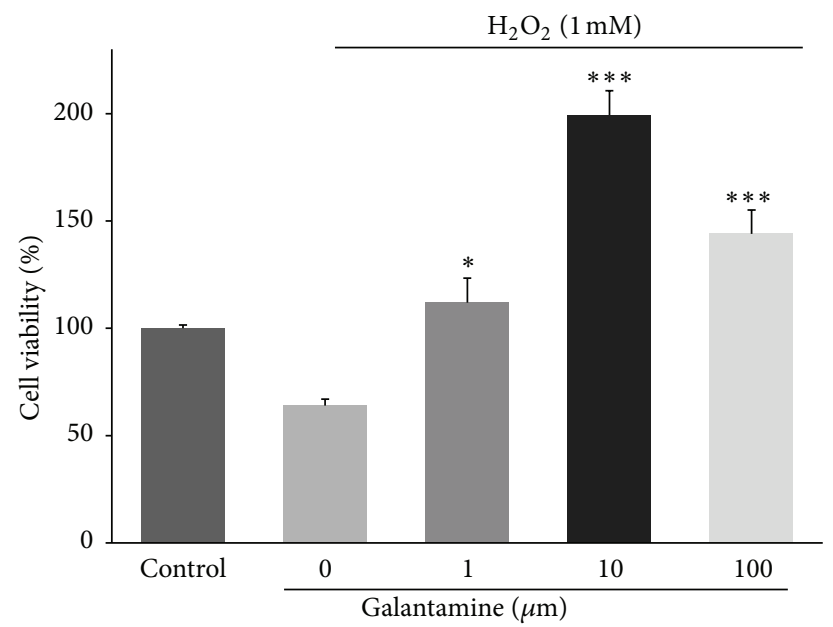

(b)

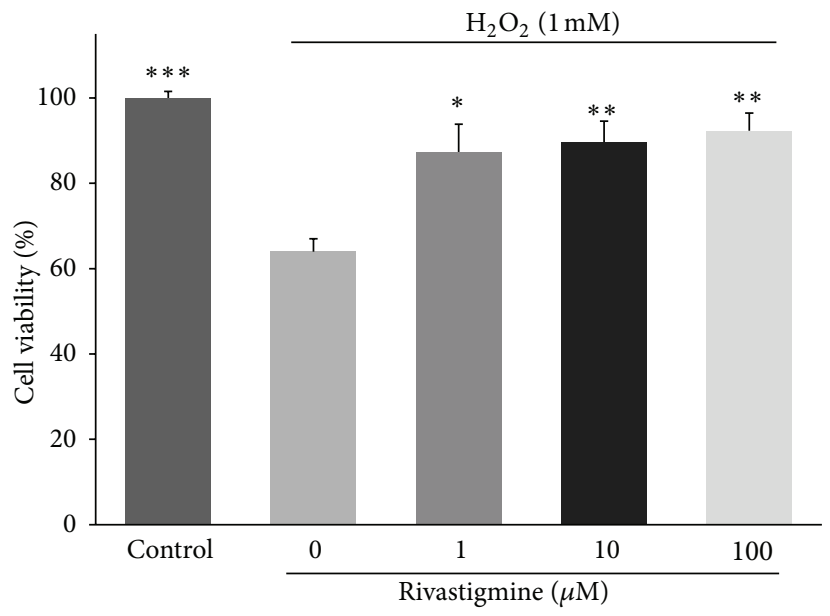

(c)

FIGURE 1: Effects of AChE inhibitors on viability of endothelial cells in the presence of $\mathrm{H}_{2} \mathrm{O}_{2}$. The HUVECs were seeded overnight in 96-well culture plate (5000 cells/well) and treated with donepezil, rivastigmine, and galantamine for $24 \mathrm{~h}$. The percent of viability was normalized against untreated control cells. Data are mean $\pm \mathrm{SD}$ of two independent experiments performed in triplicate. ${ }^{*} P<0.05,{ }^{* *} P<0.01$, and ${ }^{* * *} P<0.001$ versus untreated cells cultured in the presence of $\mathrm{H}_{2} \mathrm{O}_{2}$.

rivastigmine was significantly higher than that of untreated cells (Figure 1(c)).

\subsection{Effect of AChE Inhibitors on Endothelial Cell Apoptosis.}

Flow cytometry revealed that in control condition, $18.3 \pm$ $2.4 \%$ of HUVECs were in apoptosis stage. In the presence of $\mathrm{H}_{2} \mathrm{O}_{2}, 48.3 \pm 1.5 \%(P<0.001$ versus control) of cells were apoptotic (Figure 2(a)). The percentage of apoptotic cells significantly $(P<0.001)$ reduced by $1 \mu \mathrm{M}(20.8 \pm 2 \%), 10 \mu \mathrm{M}$ $(21.4 \pm 4.8 \%)$, and $100 \mu \mathrm{M}(19.6 \pm 0.1 \%)$ of donepezil (Figures 2(b) and 2(e)). Also, the percentage of apoptotic cells was significantly $(P<0.001)$ decreased in the cells treated with $1 \mu \mathrm{M}(30 \pm 3 \%), 10 \mu \mathrm{M}(25 \pm 2.8 \%)$, and $100 \mu \mathrm{M}(26 \pm 1.1 \%)$ of galantamine (Figures 2(c) and 2(f)). Likewise, incubation with rivastigmine could reduce the $\mathrm{H}_{2} \mathrm{O}_{2}$-induced apoptosis $(17.8 \pm 0.6 \%, 18.5 \pm 3.4 \%$, and $23.2 \pm 4.5 \%$ for 1,10 , and $100 \mu \mathrm{M}$, resp., Figures 2(d) and 2(g)).
3.3. Effect of AChE Inhibitors on Angiogenesis. Figure 3 shows the effect of ACE inhibitors on the number of vessels in chorioallantoic membrane. In the presence of 0.1 and $1 \mathrm{nmol} /$ egg of donepezil, the number of vessels increased from $100 \pm 16 \%$ (control) to $155 \pm 4 \%(P<0.01)$ and $153 \pm 4 \%$ $(P<0.05)$, respectively, (Figure 3(a)). Similarly, galantamine at $10 \mathrm{nmol} / \mathrm{egg}(158 \pm 11 \%, P<0.05)$ and rivastigmine at $0.1 \mathrm{nmol} / \mathrm{egg}(158 \pm 23 \%, P<0.05), 1 \mathrm{nmol} / \mathrm{egg}(153 \pm$ $11 \%, P<0.05)$, and $10 \mathrm{nmol} /$ egg $(170 \pm 6 \%, P<0.01)$ significantly increased angiogenesis (Figures $3(\mathrm{~b})$ and $3(\mathrm{c})$ ). The representative photographs of chorioallantoic membrane for control (PBS) and rivastigmine treated eggs are shown in Figure 4 .

\section{Discussion}

AChE inhibitors are of the most currently used therapeutics for symptomatic improvement in $\mathrm{AD}$ [9]. The beneficial 


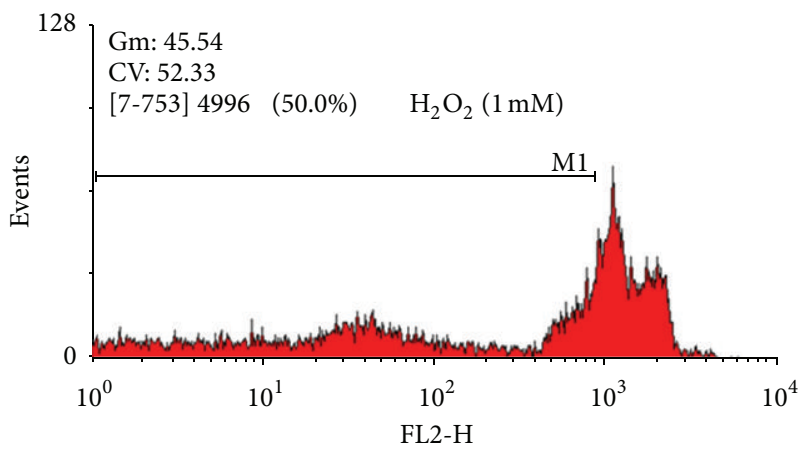

(a)

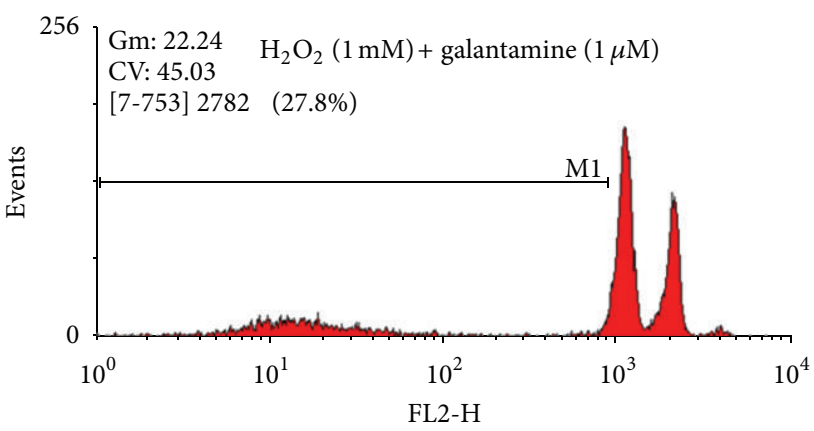

(c)

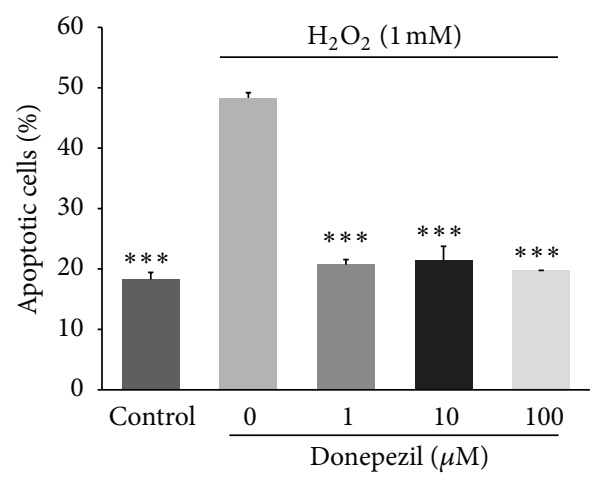

(e)

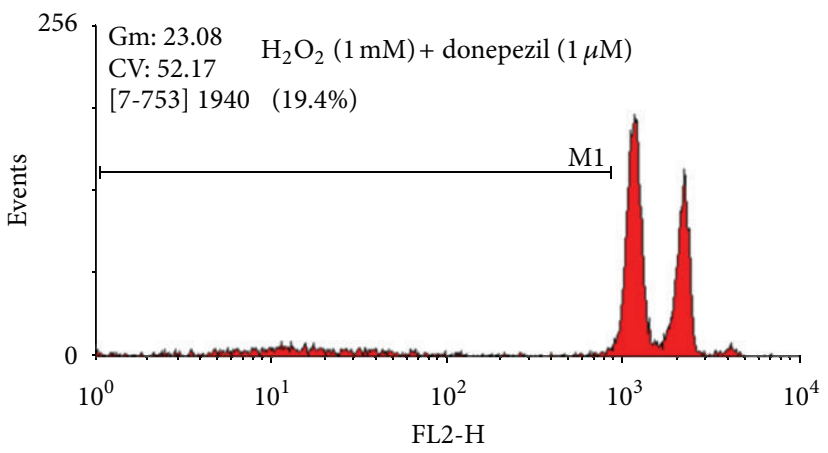

(b)

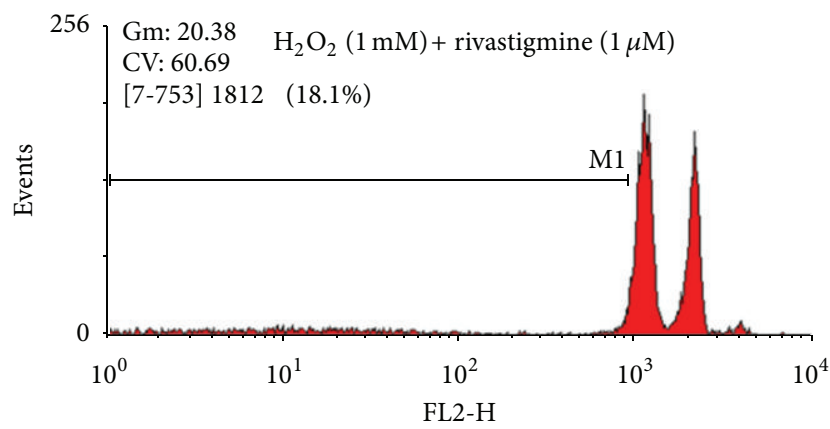

(d)

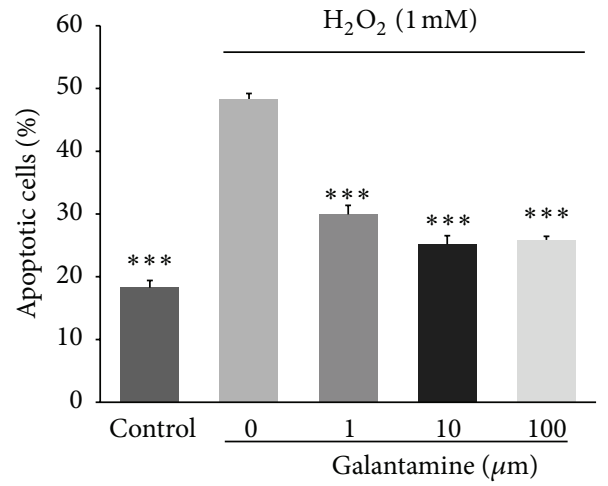

(f)

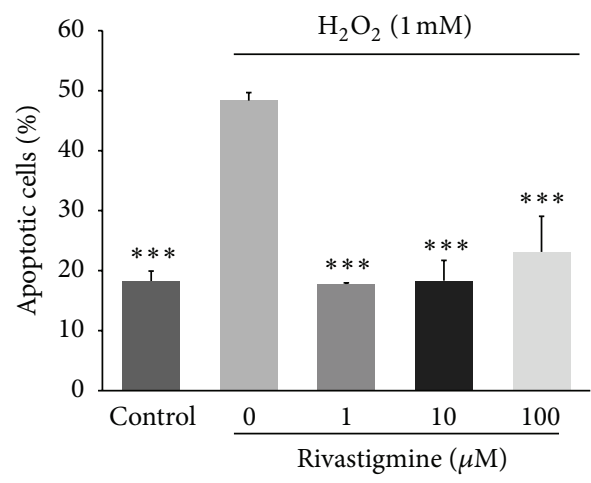

(g)

FIGURE 2: Effects of AChE inhibitors on $\mathrm{H}_{2} \mathrm{O}_{2}$-induced endothelial cells apoptosis. The HUVECs were seeded overnight in 12 -well culture plate (50000 cells/well) and treated with donepezil, rivastigmine, and galantamine for $24 \mathrm{~h}$. Data are mean \pm SD of two independent experiments performed in triplicate. ${ }^{* * *} P<0.001$ versus untreated cells cultured in the presence of $\mathrm{H}_{2} \mathrm{O}_{2}$. 


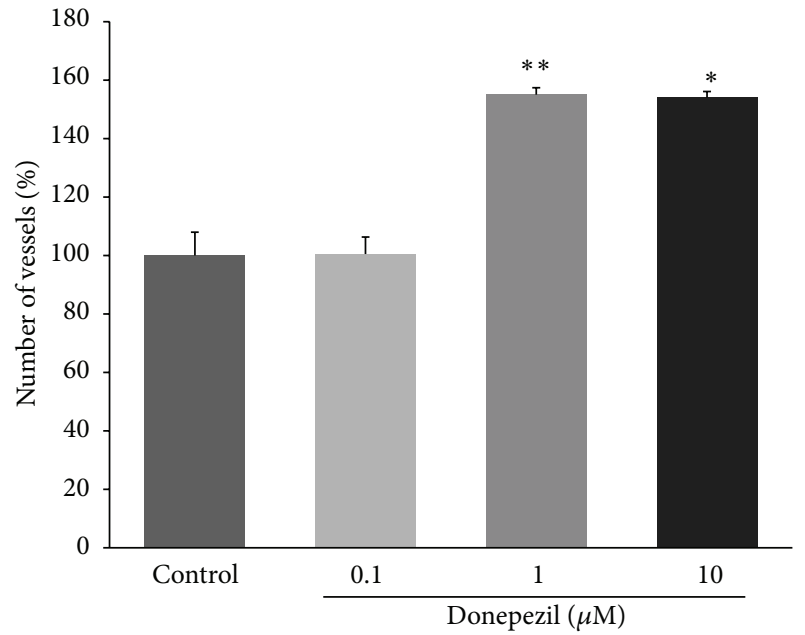

(a)

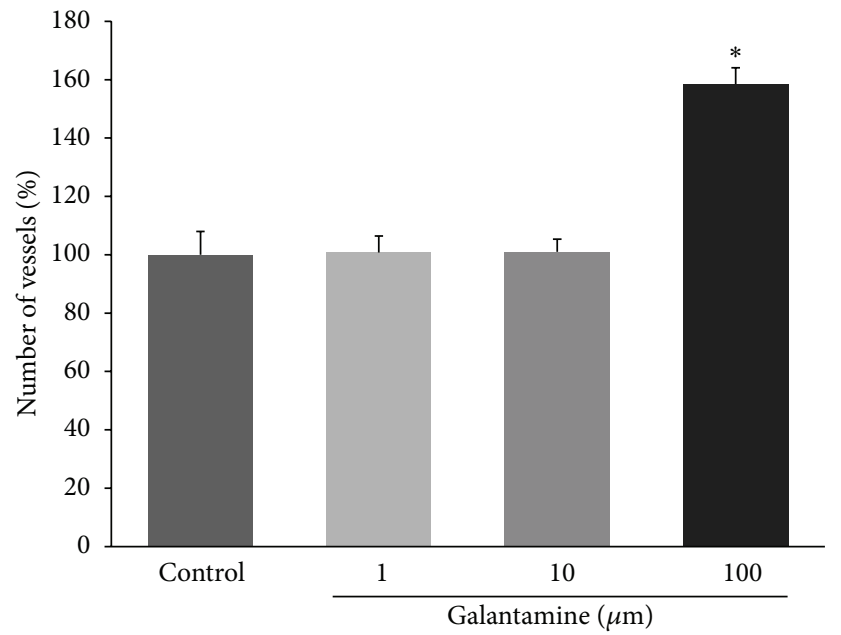

(b)

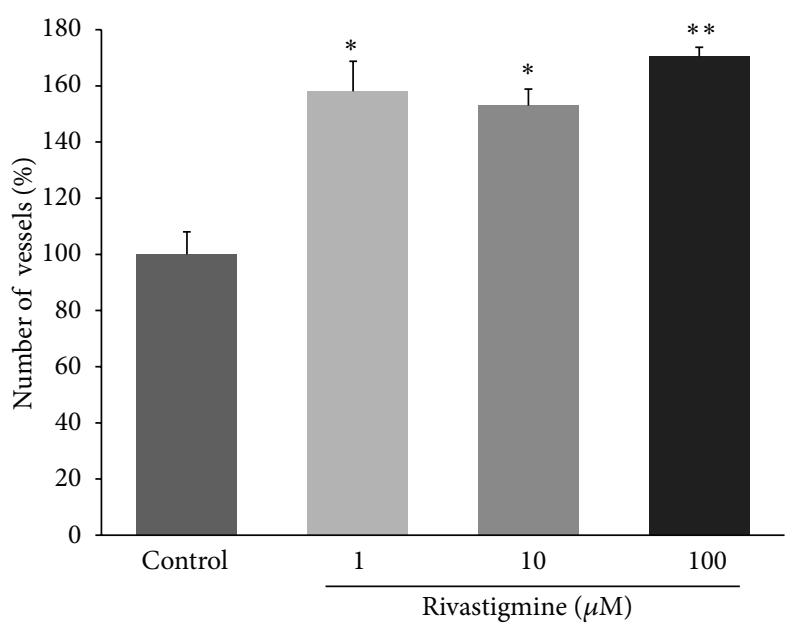

(c)

FIGURE 3: Effects of AChE inhibitors on angiogenesis in chicken chorioallantoic membrane model. The percent of vascularity was normalized against untreated control eggs. Data are mean $\pm \mathrm{SD}$ of two independent experiments performed in triplicate. ${ }^{*} P<0.05,{ }^{* *} P<0.01$, versus control.

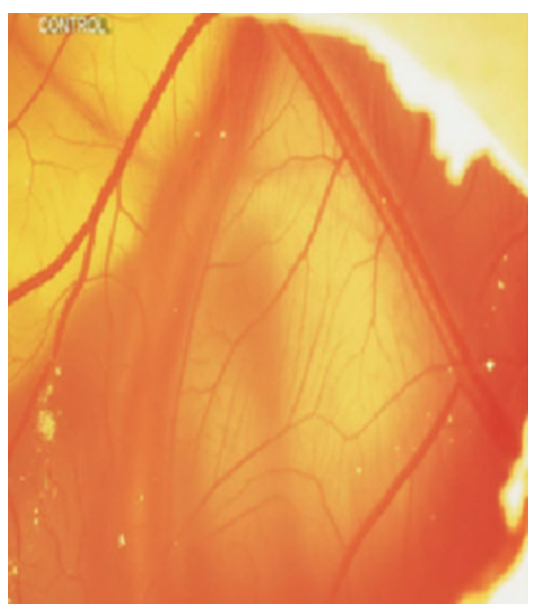

(a)

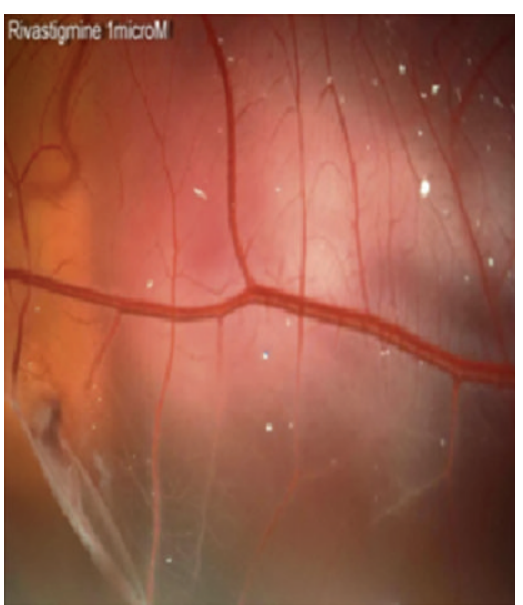

(b)

Figure 4: Effects of AChE inhibitors on angiogenesis in chicken chorioallantoic membrane model. Representative photographs of chorioallantoic membrane are shown for control (a) and rivastigmine (b) treated eggs. 
effects of AChE inhibitors are not limited to the enhancement of cholinergic activity. Other mechanisms such as inhibition of glutamate-induced neurotoxicity and reducing oxidative damage may also contribute $[16,17]$. In the present study, we demonstrated that donepezil, rivastigmine, and galantamine are capable of protecting endothelial cells against oxidative stress-induced cytotoxicity. Incubation with these AChE inhibitors attenuated the $\mathrm{H}_{2} \mathrm{O}_{2}$-induced apoptosis and restored the proliferation of cultured endothelial cells. The cytoprotective effect was observed even at concentration of 0.1 and $1 \mu \mathrm{M}$ which is comparable to the steady-state plasma concentration of $0.1-0.3 \mu \mathrm{M}$ in patients that received different doses (10-24 mg/day) of donepezil, rivastigmine, and galantamine [24].

It is well documented that structural cerebrovascular changes (vascular irregularities, reduced microvascular density, arteriolar and capillary atrophy, and endothelium degeneration) are contributed to the pathogenesis of $\mathrm{AD}[6,7]$. Recent studies have shown that endothelial cells are target for the toxic effects of glia-derived cytokines, heavily aggregated proteins, and stimuli inducing oxidative stress in AD brains [8]. Oxidative stress plays a pivotal role in cerebrovascular dysfunction and endothelial cell apoptosis [25, 26]. Activation of apoptosis can occur primarily via intrinsic or extrinsic pathways. While the intrinsic pathway originates from mitochondrial release of cytochrome $c$ and subsequent activation of caspase-3, the extrinsic pathway begins with a cell death receptor and associated stimulation of caspase8 which in turn can activate caspase-3. Activated caspase3 targets substrates that promote DNA fragmentation and cell death. $\mathrm{H}_{2} \mathrm{O}_{2}$ can activate both intrinsic and extrinsic apoptosis pathways in endothelial cells, leading to activation of caspases-3 and subsequent apoptosis [27]. Excess $\mathrm{H}_{2} \mathrm{O}_{2}$ disturbs balance between the production of reactive oxygen species and cellular antioxidant defenses (e.g., glutathione) and thereby damages macromolecules such as lipids, proteins, and nucleic acids, which trigger apoptotic pathways $[28,29]$.

Increased levels of $\mathrm{H}_{2} \mathrm{O}_{2}$ and lipid peroxidation have been shown to mediate amyloid beta neurotoxicity [19]. Also, oxidative stress is responsible for amyloid beta-induced cerebral angiopathy which is frequently observed in $\mathrm{AD}$ [26]. It has been shown that AChE inhibitors inhibit lipid peroxidation and increase glutathione level in the brain in the mice experimental model of dementia [30]. Therefore, these drugs, beside inhibition of acetylcholinesterase, may also mitigate the effects of oxidative stress on brain endothelial cell. The inhibitory effect of donepezil, rivastigmine, and galantamine on $\mathrm{H}_{2} \mathrm{O}_{2}$-induced apoptosis of endothelial cell may be involved in their beneficial effects on AD.

Our data also showed that donepezil, rivastigmine, and galantamine are able to increase angiogenesis. At present, however, the role of angiogenesis in pathogenesis of $\mathrm{AD}$ is not yet fully understood. Previous studies have shown that cognitive impairments in aging individuals are frequently associated with vascular diseases [31]. Also, conditions like atherosclerosis and diabetes which decrease vascular flow are associated with the increase of risk of AD. Decrease of vascular flow reduces amyloid- $\beta$ efflux from brain and enhances angiogenesis. Deposition of amyloid beta accelerates the process of blood vessel branching. Over time, therefore, highly branched vessel networks appear in AD brain. While early angiogenesis restores blood flow and reduces amyloid beta, the resulting hypervascularization impairs perfusion efficiency $[2,5,32,33]$. Thus, some scientists proposed that antiangiogenic drugs might be able to improve management of AD [2]. Recently, Miyazaki and colleagues reported that donepezil decreases vascular endothelial growth factor (VEGF) expression and attenuates angiogenesis in a mice hindlimb ischaemia model [34]. With the same model, however, Kakinuma and coworkers observed that donepezil enhances VEGF expression and promotes tube formation in endothelial cells [10]. In the present study, we showed that donepezil, rivastigmine, and galantamine could increase the number of vessels in chicken chorioallantoic membrane model. The proangiogenic effect was observed at dose of 0.01$10 \mathrm{nmol} / \mathrm{egg}$ which is a close approximation to the in vivo situation [24]. Although our data are in concert with the results of Kakinuma and coworkers, it is too early to draw any conclusion on the relationship between AChE inhibitors, angiogenesis, and $\mathrm{AD}$.

Taken together, in the present study, we demonstrated that donepezil, rivastigmine, and galantamine promoted angiogenesis and also protected endothelial cells against oxidative stress-induced cytotoxicity. Therefore, these effects of AChE inhibitors may be involved in their beneficial effects on $\mathrm{AD}$.

\section{Acknowledgments}

This work which is part of the Ph.D. thesis of one of the authors (Seyed Mohsen Mortazavian) was supported by a grant from Research Council of Mashhad University of Medical Sciences, Mashhad, Iran. The authors declare that they have no conflict of interests.

\section{References}

[1] P. Wang, Z.-H. Xie, Y.-J. Guo et al., "VEGF-induced angiogenesis ameliorates the memory impairment in APP transgenic mouse model of Alzheimer's disease," Biochemical and Biophysical Research Communications, vol. 411, no. 3, pp. 620-626, 2011.

[2] A. H. Vagnucci Jr. and W. W. Li, "Alzheimer's disease and angiogenesis," The Lancet, vol. 361, no. 9357, pp. 605-608, 2003.

[3] R. Donev, M. Kolev, B. Millet, and J. Thome, "Neuronal death in Alzheimer's disease and therapeutic opportunities," Journal of Cellular and Molecular Medicine, vol. 13, no. 11-12, pp. 43294348, 2009.

[4] B. S. Desai, J. A. Schneider, J.-L. Li, P. M. Carvey, and B. Hendey, "Evidence of angiogenic vessels in Alzheimer's disease," Journal of Neural Transmission, vol. 116, no. 5, pp. 587-597, 2009.

[5] D. Cameron, C. Galvin, T. Alkam et al., "Alzheimer's-related peptide amyloid- $\beta$ plays a conserved role in angiogenesis," PLoS ONE, vol. 7, Article ID e39598, 2012.

[6] P. Grammas, "Neurovascular dysfunction, inflammation and endothelial activation: implications for the pathogenesis of Alzheimer's disease," Journal of Neuroinflammation, vol. 8, article 26, 2011. 
[7] R. N. Kalaria and P. Hedera, "Differential degeneration of the cerebral microvasculature in Alzheimer's disease," NeuroReport, vol. 6, no. 3, pp. 477-480, 1995.

[8] A. B. Salmina, A. I. Inzhutova, N. A. Malinovskaya, and M. M. Petrova, "Endothelial dysfunction and repair in Alzheimertype neurodegeneration: neuronal and glial control," Journal of Alzheimer's Disease, vol. 22, no. 1, pp. 17-36, 2010.

[9] M. Mehta, A. Adem, and M. Sabbagh, "New acetylcholinesterase inhibitors for Alzheimer's disease," International Journal of Alzheimer's Disease, vol. 2012, Article ID 728983, 8 pages, 2012.

[10] Y. Kakinuma, M. Furihata, T. Akiyama et al., "Donepezil, an acetylcholinesterase inhibitor against Alzheimer's dementia, promotes angiogenesis in an ischemic hindlimb model," Journal of Molecular and Cellular Cardiology, vol. 48, no. 4, pp. 680-693, 2010.

[11] S. L. Rogers, R. S. Doody, R. C. Mohs, and L. T. Friedhoff, "Donepezil improves cognition and global function in Alzheimer disease: a 15-week, double-blind, placebo-controlled study," Archives of Internal Medicine, vol. 158, no. 9, pp. 10211031, 1998.

[12] H. Feldman, S. Gauthier, J. Hecker et al., "Efficacy and safety of donepezil in patients with more severe Alzheimer's disease: a subgroup analysis from a randomized, placebo-controlled trial," International Journal of Geriatric Psychiatry, vol. 20, no. 6, pp. 559-569, 2005.

[13] S. Gauthier, H. Feldman, J. Hecker et al., "Functional, cognitive and behavioral effects of donepezil in patients with moderate Alzheimer's disease," Current Medical Research and Opinion, vol. 18, no. 6, pp. 347-354, 2002.

[14] J. Corey-Bloom, R. Anand, and J. Veach, "A randomized trial evaluating the efficacy and safety of ENA 713 (rivastigmine tartrate), a new acetylcholinesterase inhibitor, in patients with mild to moderately severe Alzheimer's disease," International Journal of Geriatric Psychopharmacology, vol. 1, no. 2, pp. 55-65, 1998.

[15] P. N. Tariot, P. R. Solomon, J. C. Morris, P. Kershaw, S. Lilienfeld, and C. Ding, "A 5-month, randomized, placebo-controlled trial of galantamine in AD," Neurology, vol. 54, no. 12, pp. 2269-2276, 2000.

[16] S. A. Jacobson and M. N. Sabbagh, "Donepezil: potential neuroprotective and disease-modifying effects," Expert Opinion on Drug Metabolism \& Toxicology, vol. 4, pp. 1363-1369, 2008.

[17] Y. Takada-Takatori, T. Kume, M. Sugimoto et al., "Neuroprotective effects of galanthamine and tacrine against glutamate neurotoxicity," European Journal of Pharmacology, vol. 549, no. 1-3, pp. 19-26, 2006.

[18] M. Aoki, T. Nata, R. Morishita et al., "Endothelial apoptosis induced by oxidative stress through activation of NF- $\kappa$ B: antiapoptotic effect of antioxidant agents on endothelial cells," Hypertension, vol. 38, no. 1, pp. 48-55, 2001.

[19] C. Behl, J. B. Davis, R. Lesley, and D. Schubert, "Hydrogen peroxide mediates amyloid $\beta$ protein toxicity," Cell, vol. 77 , no. 6 , pp. 817-827, 1994.

[20] R. Meamar, L. Dehghani, M. Ghasemi et al., "Enalapril protects endothelial cells against induced apoptosis in Alzheimer's disease," Journal of Research in Medical Sciences, vol. 18, supplement 1, pp. S1-S5, 2013.

[21] S. M. Mortazavian, A. Ghorbani, and T. G. Hesari, "Effect of hydro-alcoholic extract of Viola tricolor and its fractions on proliferation of uterine cervix carcinoma cells," Iranian Journal of Obstetrics, Gynecology and Infertility, vol. 15, pp. 9-16, 2012.
[22] M.-A. Hajzadeh, J. T. Afshari, A. Ghorbani, and M. T. Shakeri, "Antiproliferative property of aqueous extract of garlic on human larynx tumour and non-tumour mouse fibroblast cell lines," Australian Journal of Medical Herbalism, vol. 19, no. 1, pp. 33-37, 2007.

[23] A. Carrano, J. J. M. Hoozemans, S. M. van der Vies, A. J. M. Rozemuller, J. van Horssen, and H. E. de Vries, "Amyloid beta induces oxidative stress-mediated blood-brain barrier changes in capillary amyloid angiopathy," Antioxidants and Redox Signaling, vol. 15, no. 5, pp. 1167-1178, 2011.

[24] I. H. Gomolin, C. Smith, and T. M. Jeitner, "Cholinesterase inhibitors: applying pharmacokinetics to clinical decision making," The American Journal Geriatric Pharmacotherapy, vol. 9, no. 4, pp. 259-263, 2011.

[25] S. H. Mousavi, S. A. Moallem, S. Mehri, S. Shahsavand, H. Nassirli, and B. Malaekeh-Nikouei, "Improvement of cytotoxic and apoptogenic properties of crocin in cancer cell lines by its nanoliposomal form," Pharmaceutical Biology, vol. 49, no. 10, pp. 1039-1045, 2011.

[26] G. Aliev, H. H. Palacios, E. Gasimov et al., "Oxidative stress induced mitochondrial failure and vascular hypoperfusion as a key initiator for the development of Alzheimer disease," Pharmaceuticals, vol. 3, no. 1, pp. 158-187, 2010.

[27] L. Sun, H. Y. Yau, W. Y. Wong, R. A. Li, Y. Huang, and X. Yao, "Role of TRPM2 in $\mathrm{H}_{2} \mathrm{O}_{2}$-induced cell apoptosis in endothelial cells," PLoS ONE, vol. 7, Article ID e43186, 2012.

[28] S. Elmore, "Apoptosis: a review of programmed cell death," Toxicologic Pathology, vol. 35, no. 4, pp. 495-516, 2007.

[29] W. Li, C. Busu, M. L. Circu, and T. Y. Aw, "Glutathione in cerebral microvascular endothelial biology and pathobiology: implications for brain homeostasis," International Journal of Cell Biology, vol. 2012, Article ID 434971, 14 pages, 2012.

[30] G. Saxena, S. P. Singh, R. Agrawal, and C. Nath, "Effect of donepezil and tacrine on oxidative stress in intracerebral streptozotocin-induced model of dementia in mice," European Journal of Pharmacology, vol. 581, no. 3, pp. 283-289, 2008.

[31] M. A. Kling, J. Q. Trojanowski, D. A. Wolk, V. M. Y. Lee, and S. E. Arnold, "Vascular disease and dementias: paradigm shifts to drive research in new directions," Alzheimer's \& Dementia, vol. 9, pp. 76-92, 2013.

[32] D. F. Cechetto, V. Hachinski, and S. N. Whitehead, "Vascular risk factors and Alzheimer's disease," Expert Review of Neurotherapeutics, vol. 8, no. 5, pp. 743-750, 2008.

[33] K. E. Biron, D. L. Dickstein, R. Gopaul, and W. A. Jefferies, "Amyloid triggers extensive cerebral angiogenesis causing blood brain barrier permeability and hypervascularity in Alzheimer's disease," PLoS ONE, vol. 6, no. 8, Article ID e23789, 2011.

[34] R. Miyazaki, T. Ichiki, T. Hashimoto et al., "Acetylcholinesterase inhibitors attenuate angiogenesis," Clinical Science, vol. 123, pp. 241-249, 2012. 


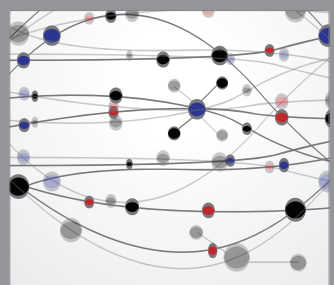

The Scientific World Journal
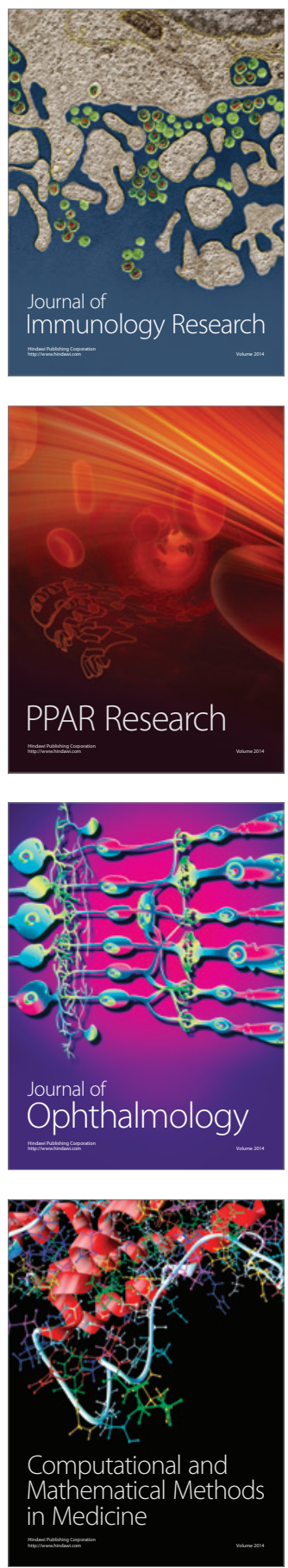

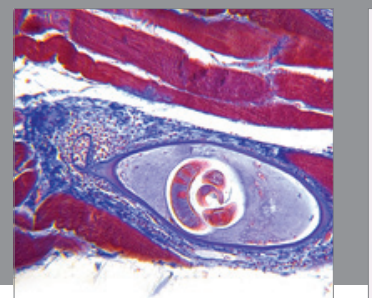

Gastroenterology

Research and Practice
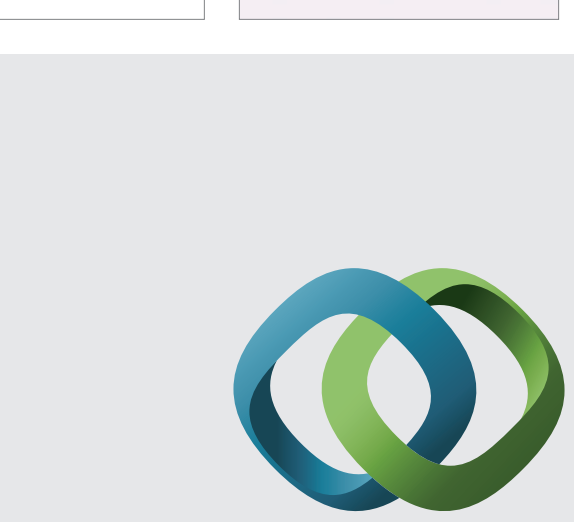

\section{Hindawi}

Submit your manuscripts at

http://www.hindawi.com
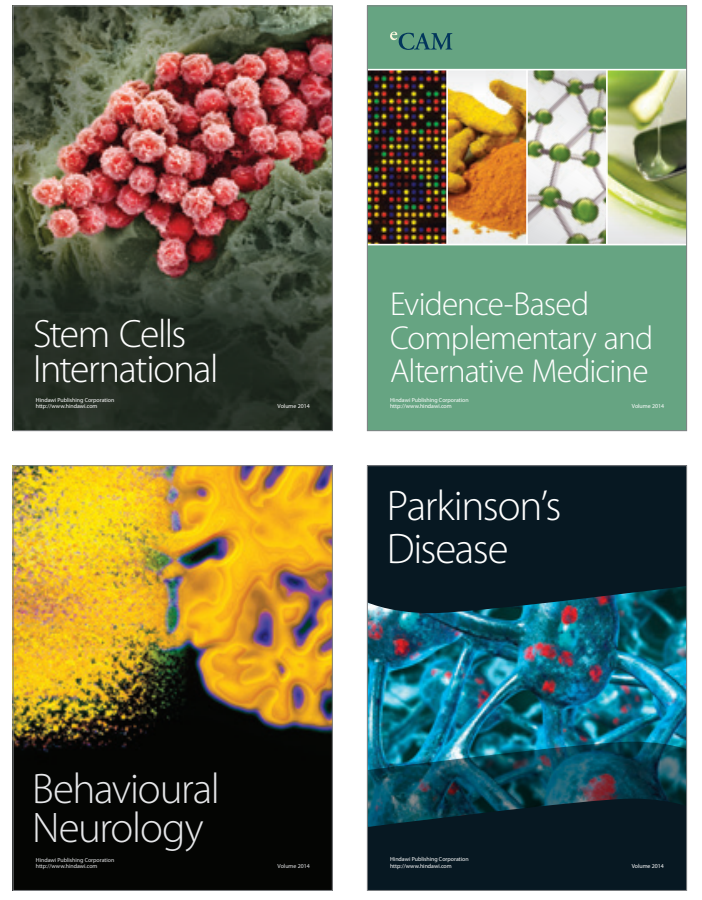
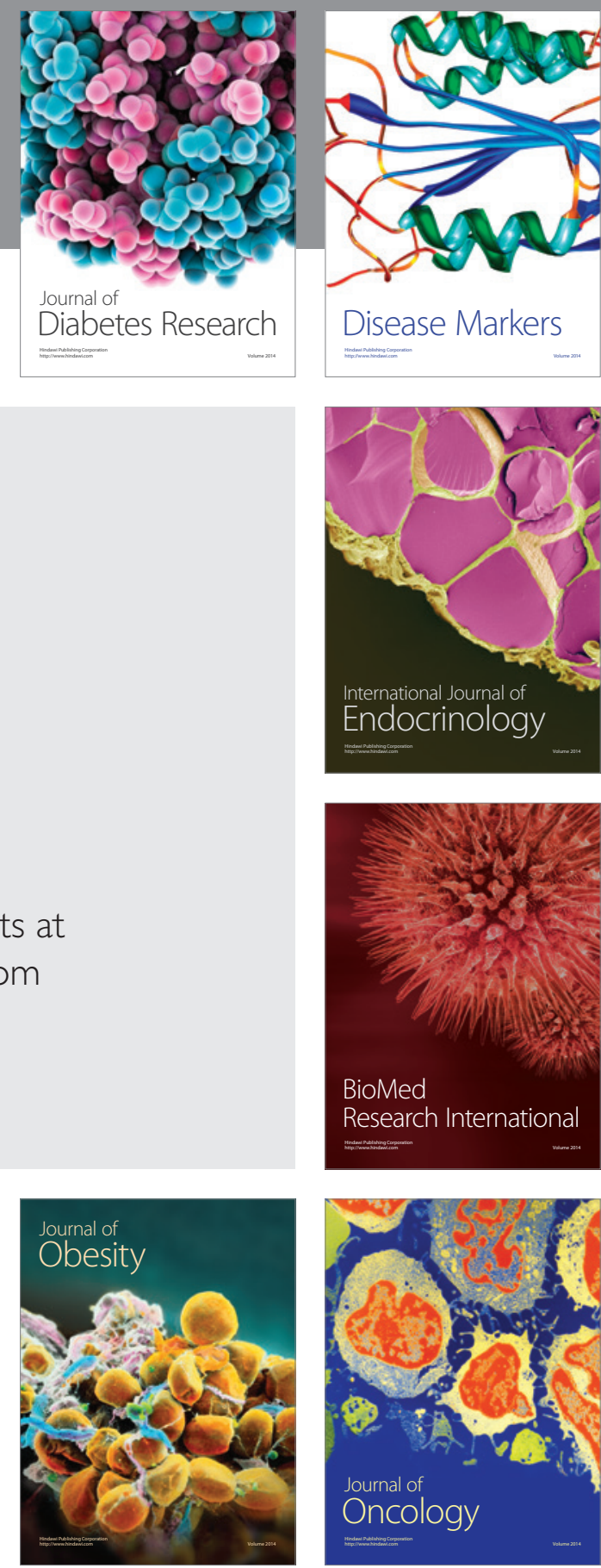

Disease Markers
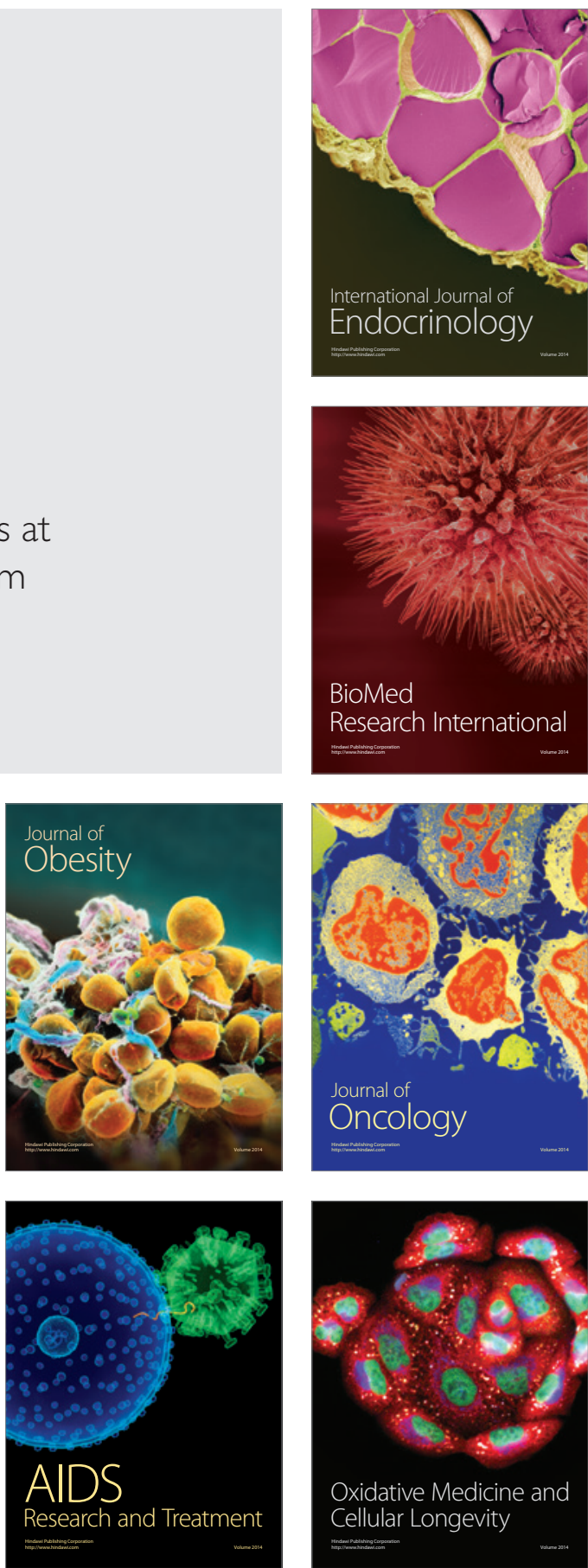